\title{
Corporate Effects of Temperature and Strain Range on the Low Cycle Fatigue Life of a Single-Crystal Superalloy DD10
}

\author{
Zhi-Dong Fan · Dong Wang • Lang-Hong Lou
}

Received: 17 February 2014/Revised: 29 May 2014/Published online: 2 December 2014

(C) The Chinese Society for Metals and Springer-Verlag Berlin Heidelberg 2014

\begin{abstract}
Low cycle fatigue behavior of a nickel-based single-crystal superalloy DD10 was investigated at 760 and $980{ }^{\circ} \mathrm{C}$ under different strain ranges. Results show that the fatigue life $\left(N_{\mathrm{f}}\right)$ of DD10 alloy exhibits different temperature dependence under various strain ranges. Under low strain range, the alloy exhibits a longer $N_{\mathrm{f}}$ at $760{ }^{\circ} \mathrm{C}$ than that at $980{ }^{\circ} \mathrm{C}$. However, under high strain range, a reverse result is obtained. This difference can be attributed to the change of dominant damage modes under various test conditions, which is manifested in different modes of crack initiation (crack nucleation and its early propagation). At $760^{\circ} \mathrm{C}$, the crack initiates at pores in subsurface due to local stress concentration. This process is mainly controlled by plastic amplitude and plastic property, but not affected by oxygen-induced damage before the crack propagates to the surface. At $980{ }^{\circ} \mathrm{C}$, the crack initiates at surface instead of pores due to the more homogeneous plastic deformation and the disharmony between the external oxidation layer and the bulk material when the strain amplitude is high. At that temperature, the process is mainly controlled by oxidation damage and strain amplitude simultaneously. Therefore, under high strain range, the crack initiation is much easier at $760{ }^{\circ} \mathrm{C}$ due to plastic deformation and the poor plasticity, while under low strain range obvious oxidation damage at $980{ }^{\circ} \mathrm{C}$ may accelerate the crack initiation.
\end{abstract}

KEY WORDS: Low cycle fatigue; Single-crystal superalloy; Temperature; Strain; Crack initiation

\section{Introduction}

Single-crystal (SX) nickel-based superalloys are good candidates for turbine blades and vanes in jet engines due to their excellent high-temperature performances [1-3]. Low cycle fatigue (LCF) is an important property for blade materials [46]. Considerable work has been conducted on LCF behaviors, especially the effects of loading waveforms, temperature, frequency, orientation, environment and microstructure on fatigue life, fatigue crack initiation, and propagation [7-13].

Available online at http://link.springer.com/journal/40195

Z.-D. Fan · D. Wang $(\bowtie) \cdot$ L.-H. Lou

Institute of Metal Research, Chinese Academy of Sciences,

Shenyang 110016, China

e-mail: dwang@imr.ac.cn
It is traditionally believed that the fatigue life $\left(N_{\mathrm{f}}\right)$ decreases with the increasing total strain amplitude $\left(\varepsilon_{\text {total }}\right)$ under the constant temperature [11, 14-19]. However, the temperature dependence of $N_{\mathrm{f}}$ also exhibits a strong dependence on $\varepsilon_{\text {total }}$, and $N_{\mathrm{f}}$ of many superalloys does not monotonously decrease with the increasing temperature. Under low strain range, $N_{\mathrm{f}}$ decreases sharply with increasing temperature; while under high strain range, this trend seems to be weakened. The $N_{\mathrm{f}}$ of some alloys at high temperature is even longer than that at low temperature. This abnormal phenomenon has been noticed by many researchers $[8,15,17,20-24]$, whereas the mechanism behind is still under debate. Some researchers [15, 16, 25] attributed this phenomenon to the variation of dominant fatigue damages under different test conditions. Under low strain range, the fatigue time is relatively long. $N_{\mathrm{f}}$ is severely affected by the oxidation and creep damage. These two factors can accelerate trans-granular crack initiation and assist inter- 

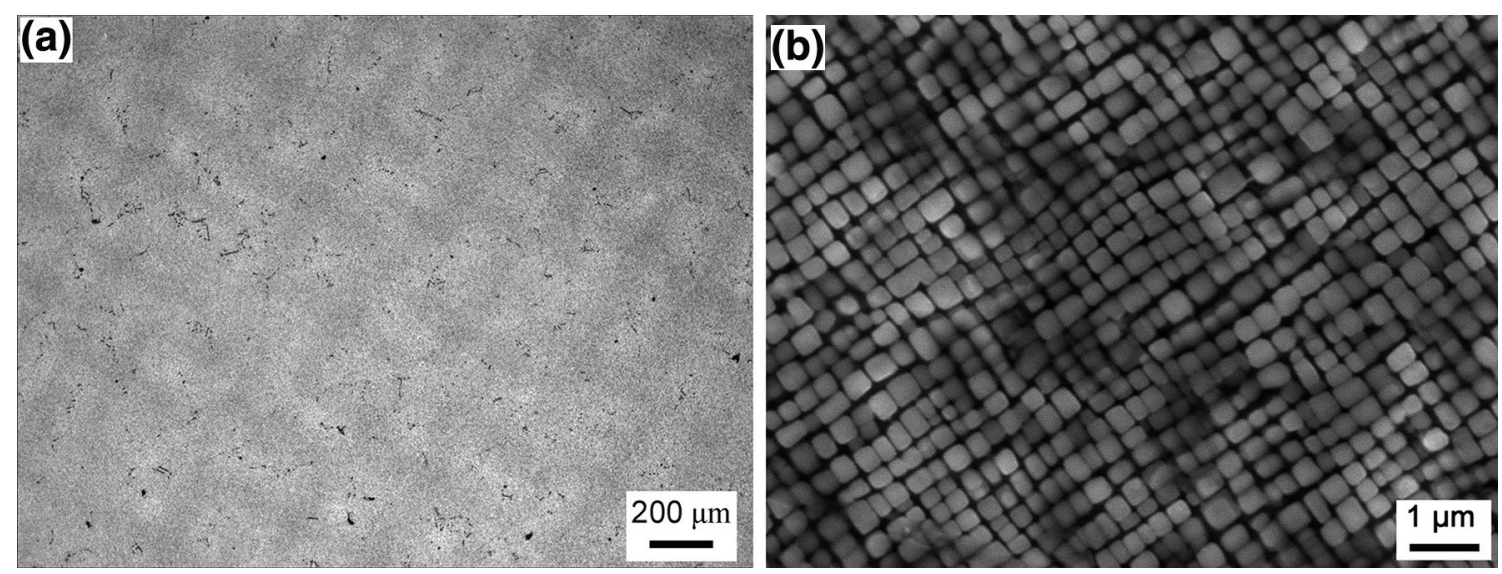

Fig. 1 OM image a, SEM image b showing the microstructure of DD10 after solution heat treatment

granular cracking progress. It is obvious that the higher the temperature is, the more apparent the oxidation and creep damage are. Therefore, a shorter $N_{\mathrm{f}}$ is expected at higher temperature and under low strain range. With the increment of $\varepsilon_{\text {total }}, N_{\mathrm{f}}$ decreases sharply, the effect of oxidation and creep damage can be neglected under this condition. However, the corresponding explanation for the converse temperature dependence of $N_{\mathrm{f}}$ in high strain range has not been proposed yet $[15,16,25]$. In addition, it should be mentioned that the viewpoint mentioned above is obtained mainly in columnar grain superalloys and polycrystal superalloys. The abnormal temperature dependence of $N_{\mathrm{f}}$ for $\mathrm{SX}$ superalloys has not been reported.

It is recognized that the LCF life usually consists of three stages, namely crack initiation, crack steady propagation, and the crack fast propagation. According to engineering standard, crack initiation (micro-crack nucleation and early propagation) accounts for most part of fatigue life, and those factors related with this process should be emphasized [20]. However, the relationship between the crack initiation mode and the temperature dependence of fatigue life in different strain ranges still calls for further investigation.

In this paper, strain-controlled LCF tests on SX superalloys DD10 were conducted at 760 and $980{ }^{\circ} \mathrm{C}$ under different strain ranges. Process of crack initiation under different test conditions was analyzed and discussed.

\section{Experimental}

Nickel-based SX superalloy DD10 used in the present experiments contains $13 \mathrm{wt} \% \mathrm{Cr}, 4 \mathrm{wt} \% \mathrm{Co}, 7.8 \mathrm{wt} \%$ $(\mathrm{Al}+\mathrm{Ti}), 11-13 \mathrm{wt} \%(\mathrm{Ta}+\mathrm{W}+\mathrm{Mo})$, with minor $\mathrm{C}$ and $\mathrm{B}$, and $\mathrm{Ni}$ in balance. The SX specimens were fabricated by a vacuum induction furnace with high-rate solidification technique. Those bars within $8^{\circ}$ of the [001] direction were solution treated at $1,250{ }^{\circ} \mathrm{C}$ for $3 \mathrm{~h}$ in air, precipitation heat treated at $1,100{ }^{\circ} \mathrm{C}$ for $5 \mathrm{~h}$, and aged at $870{ }^{\circ} \mathrm{C}$ for $24 \mathrm{~h}$. The as heat-treated microstructure contains a precipitation of cuboidal $\gamma^{\prime}$ particles, with size of about $0.4 \mu \mathrm{m}$ and volume fraction of about $65 \%$. No residual $\gamma / \gamma^{\prime}$ eutectics are visible, as depicted in Fig. 1.

Prior to LCF tests, tensile tests were carried out at 760 and $980^{\circ} \mathrm{C}$ in air. LCF specimens with $5 \mathrm{~mm}$ in diameter and $12 \mathrm{~mm}$ in gage length were machined from heat-treated bars. A servo hydraulic testing machine was used to perform the fatigue tests at 760 and $980{ }^{\circ} \mathrm{C}$. The total axial strain was measured and controlled by an extensometer mounted upon the ledges of specimens. The total strain range varied from $\pm 1.4 \%$ to $\pm 2.4 \%$ at $760{ }^{\circ} \mathrm{C}$ and from $\pm 0.8 \%$ to $\pm 2.4 \%$ at $980{ }^{\circ} \mathrm{C}$ with a fully reversed straincontrolled push-pull mode, i.e., $R=-1$. The strain rate was $5 \times 10^{-3} \mathrm{~s}^{-1}$, applied in a triangular waveform. The temperature fluctuation over the gage length was maintained within $\pm 2{ }^{\circ} \mathrm{C}$; all the tests were performed in air. Interrupted experiments were also conducted at different cycle numbers in order to figure out whether the crack initiation occurred. After the LCF tests, longitudinal sections, fracture surfaces, and exterior surfaces were examined by scanning electron microscopy (SEM) to identify modes of fatigue crack initiation.

\section{Results}

\subsection{LCF Life}

The classical Manson-Coffin relationship is widely used to describe the strain-controlled low cycle fatigue behavior. The total strain amplitude can be separated into the plastic and elastic strain amplitude, expressed as follows [26]: 
Manson-Coffin equation

$\Delta \varepsilon_{\mathrm{p}} / 2=\varepsilon_{\mathrm{f}}^{\prime}\left(2 N_{\mathrm{f}}\right)^{-c}$,

Basquin equation

$\Delta \sigma_{\mathrm{t}} / 2=\sigma_{\mathrm{f}}^{\prime}\left(2 N_{\mathrm{f}}\right)^{-b}$,

$\frac{\Delta \varepsilon_{\text {total }}}{2}=\frac{\Delta \varepsilon_{\mathrm{e}}}{2}+\frac{\Delta \varepsilon_{\mathrm{p}}}{2}=\frac{\sigma_{\mathrm{f}}^{\prime}}{\mathrm{E}}\left(2 N_{\mathrm{f}}\right)^{-b}+\varepsilon_{\mathrm{f}}^{\prime}\left(2 N_{\mathrm{f}}\right)^{-c}$,

where $\Delta \varepsilon_{\mathrm{e}} / 2$ is the elastic strain amplitude, $\Delta \varepsilon_{\mathrm{p}} / 2\left(\Delta \varepsilon_{\text {total }} /\right.$ $\left.2-\Delta \varepsilon_{\mathrm{e}} / 2\right)$ is the calculated plastic strain amplitude, $\Delta \sigma_{\mathrm{t}}$ is the full stress range, $N_{\mathrm{f}}$ is the number of cycles to failure, $\sigma_{\mathrm{f}}^{\prime}$ and $\varepsilon_{\mathrm{f}}^{\prime}$ are the fatigue strength and fatigue ductility coefficient, respectively, $b$ and $c$ are the material's constants for a selected alloy, and $E$ is the Young's modulus.

The relationships of $\Delta \varepsilon_{\text {total }} / 2, \Delta \varepsilon_{\mathrm{e}} / 2$, and $\Delta \varepsilon_{\mathrm{p}} / 2$ versus $N_{\mathrm{f}}$ at different temperatures are plotted respectively in Fig. 2. It is noted that DD10 shows a decrease in $N_{\mathrm{f}}$ with increasing strain amplitude at both temperatures, the same as most nickel-based superalloy [11, 14-21, 27]. At all testing strain levels, the values of $\Delta \varepsilon_{\mathrm{p}} / 2$ in alloy DD10 are much smaller than $\Delta \varepsilon_{\mathrm{e}} / 2$ at both temperatures, indicating that there is no transition fatigue life $\left(N_{\mathrm{tf}}\right)$ that $\Delta \varepsilon_{\mathrm{p}} / 2=\Delta \varepsilon_{\mathrm{e}} /$ 2. This result disagrees with Yao [24]. In addition, the $\Delta \varepsilon_{\mathrm{p}}$ of DD10 at $760{ }^{\circ} \mathrm{C}$ is much smaller than that at $980{ }^{\circ} \mathrm{C}$ under the condition of identical $\Delta \varepsilon_{\text {total }}$.

The fatigue parameters are listed in Table 1, and the corresponding parameters of tensile properties are listed in Table 2. It demonstrated that DD10 exhibits superior plastic properties but a poor strength at $980{ }^{\circ} \mathrm{C}$. In Table 2, $\varepsilon_{\text {yield }}$ refers to the strain amplitude when the alloy yields.

For engineering applications, an important property of a selected alloy under LCF test is the fatigue life as a function of total strain amplitude [28]. The strain fatigue data were analyzed at 760 and $980{ }^{\circ} \mathrm{C}$, respectively, using an apparent linear fit program according to Eq. (3). The result is presented in Fig. 3 .

The temperature dependence of fatigue life is contrary under different strain ranges. Under high strain range, alloy DD10 at $980{ }^{\circ} \mathrm{C}$ exhibits a longer fatigue life than that at $760{ }^{\circ} \mathrm{C}$, while a reverse result is gained under low strain range. Similar results were reported by other researchers $[11,15,16,24]$. It should be noted that the slope of the $\Delta \varepsilon_{\text {total }} / 2$ versus $2 N_{\mathrm{f}}$ curve at $980{ }^{\circ} \mathrm{C}$ is larger than that at $760{ }^{\circ} \mathrm{C}$, which indicates $N_{\mathrm{f}}$ varies more acutely with $\Delta \varepsilon_{\text {total }} /$ 2 at $760{ }^{\circ} \mathrm{C}$ than at $980{ }^{\circ} \mathrm{C}$. In other words, $N_{\mathrm{f}}$ is more sensitive to strain variation at $760{ }^{\circ} \mathrm{C}$.

\subsection{Fracture Behavior}

At $760{ }^{\circ} \mathrm{C}$, the fracture surface is characterized by one or more cleavage-like facets inclined to the loading axis at all strain levels. This morphologies of stage I fracture surface are in good agreement with observations on many other nickel-based superalloys under similar conditions [11, 19, 20, 29, 30]. Typical images of the fatigue fracture morphology at $760{ }^{\circ} \mathrm{C}$ are presented in Fig. 4.
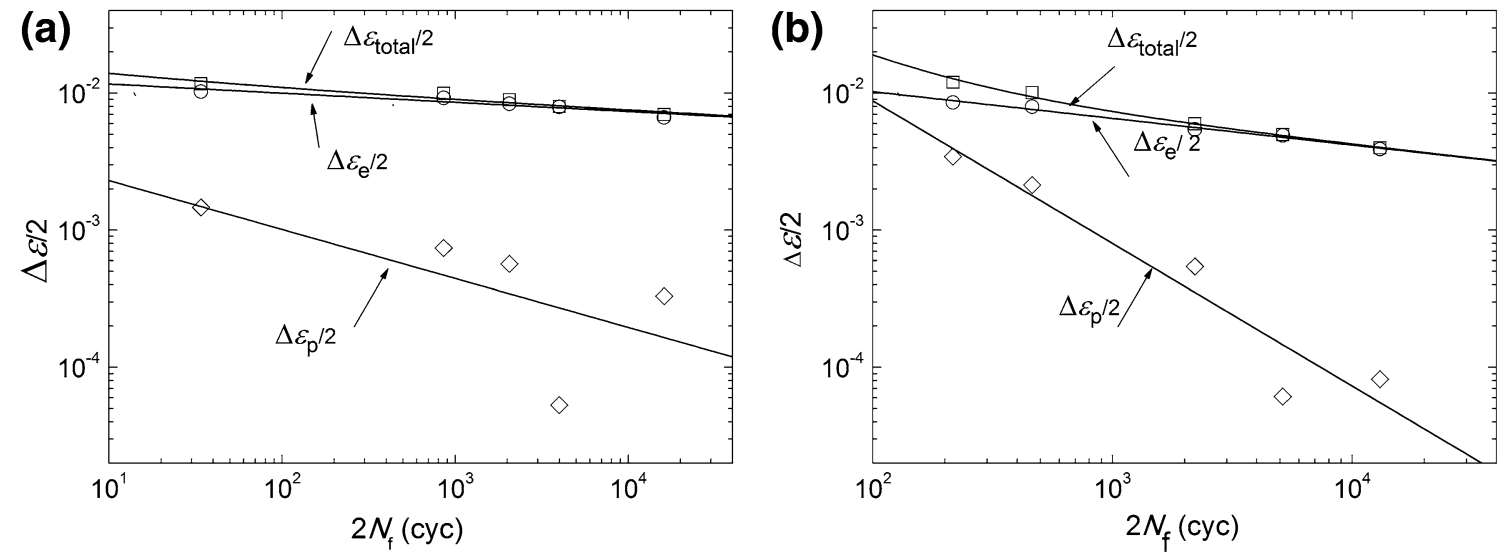

Fig. 2 Total, elastic, and plastic strain amplitude versus number of cycles to failure of DD10 at $760{ }^{\circ} \mathrm{C} \mathbf{a}, 980{ }^{\circ} \mathrm{C} \mathbf{~ b}$

Table 1 Strain fatigue parameters of DD10 alloy at 760 and $980{ }^{\circ} \mathrm{C}$

\begin{tabular}{lllllrrr}
\hline Temperature $\left({ }^{\circ} \mathrm{C}\right)$ & $\varepsilon_{\mathrm{f}}^{\prime}(\%)$ & $c$ & $\sigma_{\mathrm{f}}^{\prime}(\mathrm{MPa})$ & $b$ & $E(\mathrm{GPa})$ & $K(\mathrm{MPa})$ & $n^{\prime}$ \\
\hline 760 & 0.523 & 0.36 & 1,084 & 0.0669 & 102 & 1,540 \\
980 & 1.054 & 1.04 & 1,832 & 0.1946 & 73 & 0.0751 \\
\hline
\end{tabular}


Table 2 Tensile properties of heat-treated DD10 alloy at 760 and $980{ }^{\circ} \mathrm{C}$

\begin{tabular}{llllll}
\hline $\begin{array}{l}\text { Temperature } \\
\left({ }^{\circ} \mathrm{C}\right)\end{array}$ & $\begin{array}{l}\varepsilon_{\mathrm{f}} \\
(\%)\end{array}$ & $\begin{array}{l}\text { Reduced area } \\
(\%)\end{array}$ & $\begin{array}{l}\varepsilon_{\text {yield }} \\
(\%)\end{array}$ & $\begin{array}{l}\sigma_{0} \\
(\mathrm{MPa})\end{array}$ & $E(\mathrm{GPa})$ \\
\hline 760 & 15.9 & 15.9 & 0.89 & 1,038 & 98.2 \\
980 & 30.4 & 30.7 & 0.42 & 392 & 79.3 \\
\hline
\end{tabular}

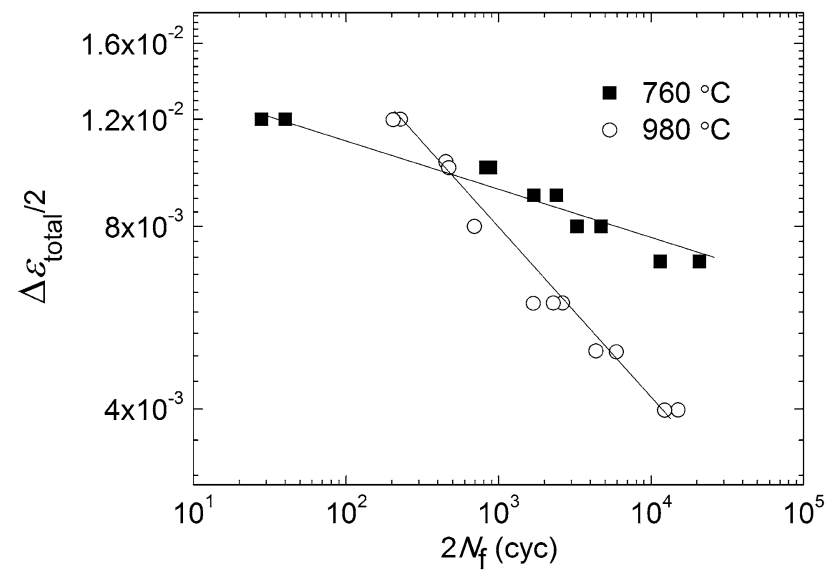

Fig. 3 Total strain amplitude $\left(\Delta \varepsilon_{\text {totoal }} / 2\right)$ versus number of cycles $\left(2 N_{\mathrm{f}}\right)$ to failure of DD10 at 760 and $980{ }^{\circ} \mathrm{C}$

The fatigue crack initiation site lies at a small rough plain in the vicinity of surface. Further observation reveals that fatigue crack initiates at defects in subsurface, such as micro-pores and script carbides. It is found that fatigue crack initiates at a cluster of micro-pore and script carbide (Fig. $4 \mathrm{~b}$ ), and then propagates along the slip bands until fracture (Fig. 4c). In addition, a few pits, which are believed to be the trace of carbides destroyed by oxidation, are dispersedly distributed on the exterior surface (Fig. 4c). However, these pits failed to develop into crack initiation sites.
At $980{ }^{\circ} \mathrm{C}$, the fracture surface is characterized by a stage II rough plane macroscopically normal to the loading axis at all strain levels. Figure 5 shows representative images of fracture texture of DD10 at $980{ }^{\circ} \mathrm{C}$. It is found that fatigue crack initiates at surface rather than at the internal micro-pores (Fig. 5a), similar crack initiation sites are visible in other specimens. Many micro-cracks arisen from oxidation damage are emerged at lateral surface (Fig. 5c, d), but only part of them continues to propagate until final fatigue failure. Additionally, slip bands are rarely observed around the crack root or the crack tip, indicating that local plastic deformation is not common in alloy DD10 at $980{ }^{\circ} \mathrm{C}$.

Typical plots on interrupted specimens shown in Fig. 6 demonstrated that in specimens interrupted after 1,500 cyc at $760{ }^{\circ} \mathrm{C}$ with $\Delta \varepsilon_{\text {total }} / 2=0.7 \%$, no micro-crack is observed in evidence around micro-pore at subsurface (Fig. 6a, b), whereas specimens at $980{ }^{\circ} \mathrm{C}$ almost failed through 1,500 cyc with $\Delta \varepsilon_{\text {total }} / 2=0.7 \%$. Similarly, for specimens interrupted after 30 cycles at $980{ }^{\circ} \mathrm{C}$ with $\Delta \varepsilon_{\text {total }} / 2=1.2 \%$, no micro-crack is evidenced at surface (Fig. 6c), but specimens at $760{ }^{\circ} \mathrm{C}$ almost have failed through $30 \mathrm{cyc}$ at the same strain level. It is worth noting that carbides at surface are easily destroyed by oxidation damage, and it tends to split along the interface between carbides and matrix at $980{ }^{\circ} \mathrm{C}$ (Fig. 6d).

\section{Discussion}

\subsection{Assessment of Fatigue Crack Initiation under Different Testing Conditions}

At $760{ }^{\circ} \mathrm{C}$, the interaction between defects and slip bands results in intense stress concentration around these defects in the subsurface [31]. Based on the defect sizes, the stress
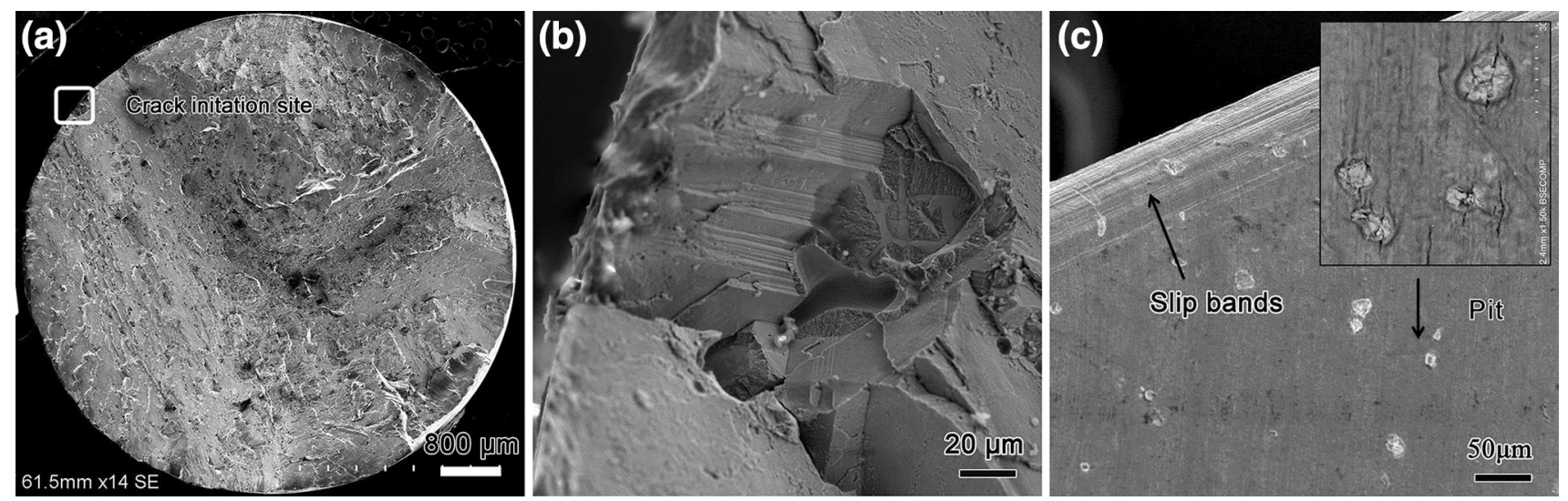

Fig. 4 SEM images of fracture after LCF at $760{ }^{\circ} \mathrm{C}$ with $\Delta \varepsilon_{\text {total }} / 2=1.2 \%$ : a macroscopical fracture topography; $\mathbf{b}$ crack initiation site; $\mathbf{c}$ slip bands on outer surface 

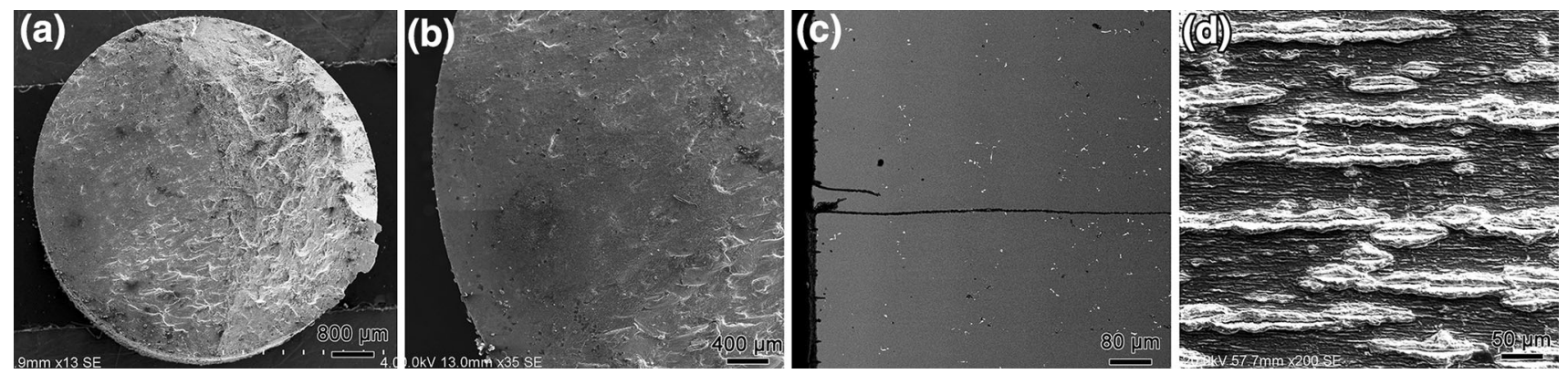

Fig. 5 SEM images of fracture surfaces after LCF at $980{ }^{\circ} \mathrm{C}$ with $\Delta \varepsilon_{\text {total }} / 2=1.2 \%$ : a macroscopical fracture topography; b crack initiation site; c longitudinal section; $\mathbf{d}$ cracks at the exterior surface
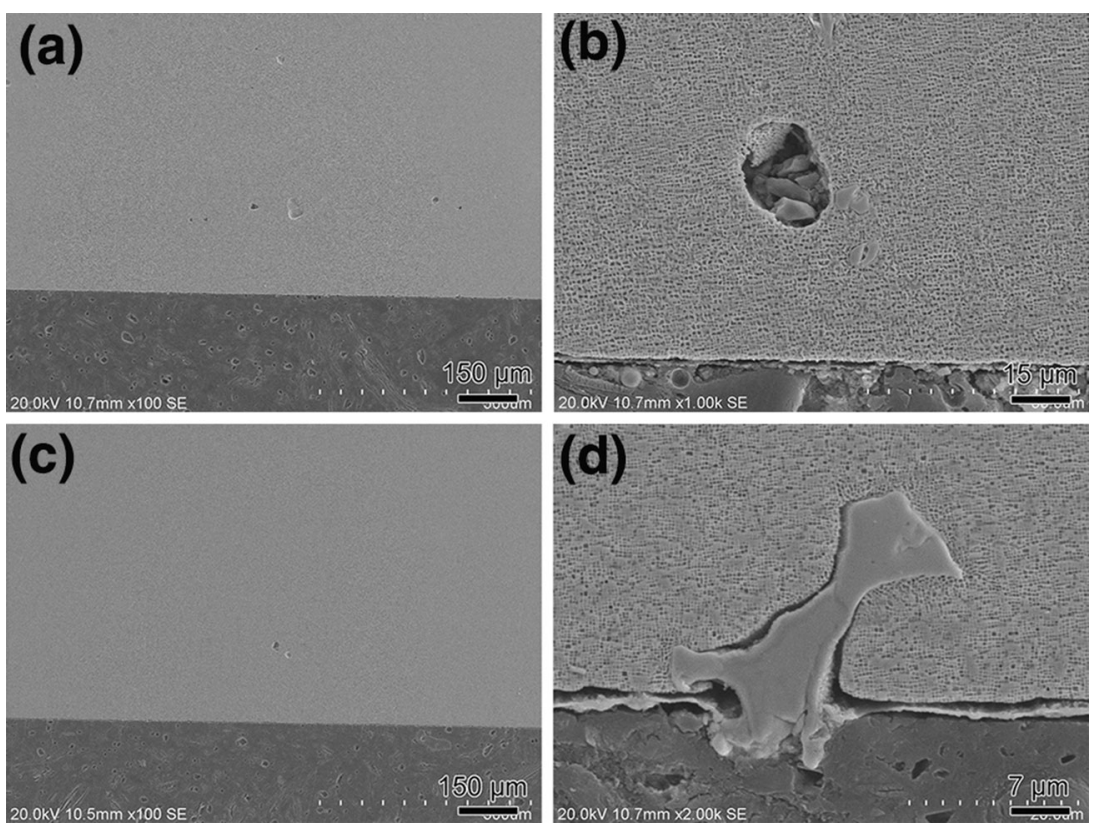

Fig. 6 SEM images of longitudinal section for specimens interrupted after 1,500 cyc at $760{ }^{\circ} \mathrm{C}$ with $\Delta \varepsilon_{\text {totoal }} / 2=0.7 \%$ a, b, that after 30 cyc at $980{ }^{\circ} \mathrm{C}$ with $\Delta \varepsilon_{\text {totoal }} / 2=1.2 \% \mathbf{c}, \mathbf{d}$

intensity factor, $K$, is calculated by using the following formulae:

$K=a \Delta \sigma \sqrt{\pi \sqrt{A_{\text {defect }}}}$

where $\Delta \sigma$ refers to the stress amplitude, $A_{\text {defect }}$ refers to area of defects projected on a plane normal to the loading axis, and $a$ and $A_{\text {defect }}$ can be regarded as constants for a given alloy with the same directional solidification parameters [32]. The precondition of crack initiation is that $K$ reaches a threshold value $K_{\text {th }}$, namely that $\Delta \sigma$ simultaneously reaches the corresponding peak. It is worth noting that the $\Delta \sigma$ mentioned in Eq. (4) actually refers to the local stress amplitude around the micro-pore, because $\Delta \sigma$ will increase with the increasing number of cycles rather than remain constant after several cycles as $\Delta \sigma_{\mathrm{t}}$ does. Actually, $\Delta \sigma$ is determined by the accumulation of dislocation amount around the micro-pore in every cycle and the cyclic number. At $760{ }^{\circ} \mathrm{C}$, activated slip systems of specimens with crystal orientation around [001] are limited and dislocation climbing is embarrassed. Slip bands are obstructed by defects at subsurface easily (Fig. 4b). Consequently, $\Delta \sigma$ around defects increases sharply in a short time, and so does $K$ [31]. It should be emphasized that the initiation process in this case is not responsive to the oxidation damage until the micro-crack reaches the exterior surface, and $\Delta \varepsilon_{\mathrm{p}}$ is the key factor in this process. It is also the reason why the $N_{\mathrm{f}}$ is more sensitive to the variation of $\Delta \varepsilon_{\text {total }}$ at $760{ }^{\circ} \mathrm{C}$ in comparison to $980{ }^{\circ} \mathrm{C}$, just the same as reported [17].

Fatigue crack initiation does not occur at casting defects at $980{ }^{\circ} \mathrm{C}$, due to the low local stress concentration around these casting defects induced by the more homogeneous 

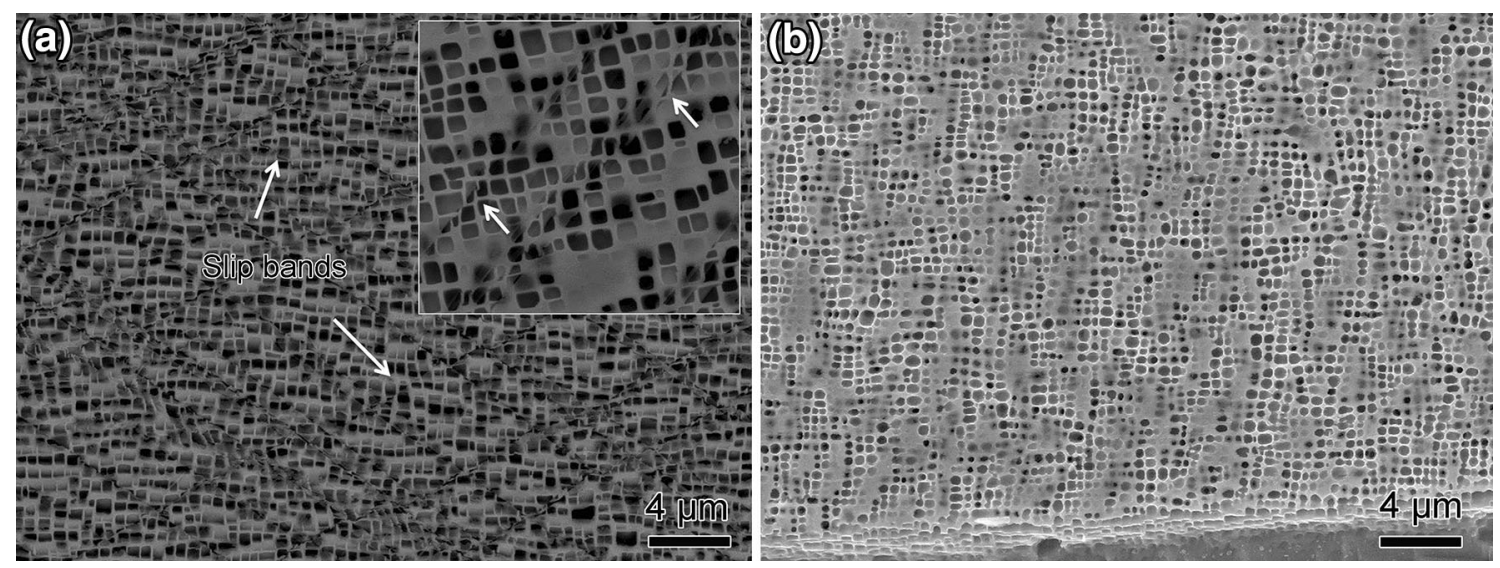

Fig. 7 SEM images of longitudinal section for failure specimens at $760{ }^{\circ} \mathrm{C}$ with $\Delta \varepsilon_{\text {totoal }} / 2=0.7 \%$ a, $980{ }^{\circ} \mathrm{C}$ with $\Delta \varepsilon_{\text {totoal }} / 2=0.4 \% \mathbf{b}$

(a)

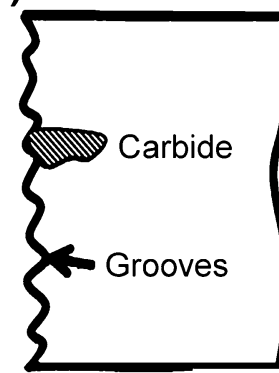

(b)

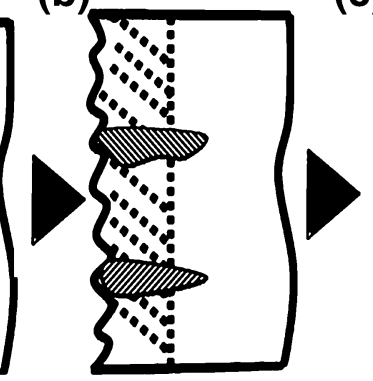

(c)

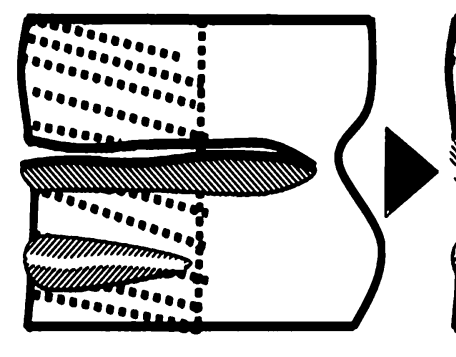

(d)

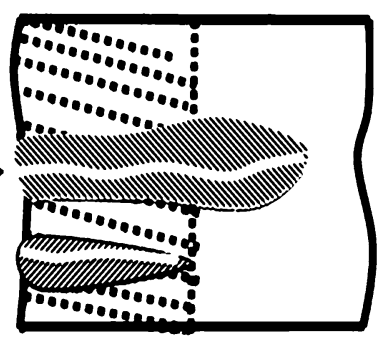

Fig. 8 Illustration of crack initiation for alloys DD10 at $980{ }^{\circ} \mathrm{C}$ : a original surface; b exterior oxidation layer; c oxide ruptures due to disharmony when deforming; $\mathbf{d}$ air passage to crack tip

deformation at this temperature. However, in DD10 alloy at $760{ }^{\circ} \mathrm{C}$, deformation mainly occurs in the slip bands, which are not common at $980{ }^{\circ} \mathrm{C}$ as at $760{ }^{\circ} \mathrm{C}$ (Fig. 7).

According to the present results from the failed and interrupted specimens, at $980{ }^{\circ} \mathrm{C}$, the fatigue crack initiates at surface as illustrated in Fig. 8. Defects at surface, such as carbides and micro-grooves (Fig. 8a), suffer much more severe oxidation damage. An oxidation layer originally forms at the exterior surface (Fig. 8b), but this layer cannot be elongated homogenously on the bulk material. Due to the disharmony between exterior oxidation layer and bulk material when deforming, micro-crack is likely to initiate at such oxidized sites (Figs. 6d, 8c). Then, oxygen reaches the crack tip through the micro-crack (Fig. 8d) and accelerates the crack propagation. The crack initiation process in this case is influenced by oxidation damage and strain amplitude simultaneously.

\subsection{Temperature Dependence of Fatigue Life under Different Strain Ranges}

The crack initiation process is mainly controlled by plastic strain amplitude at $760{ }^{\circ} \mathrm{C}$, while by oxidation damage together with strain amplitude at $980{ }^{\circ} \mathrm{C}$. Therefore, the $N_{\mathrm{f}}$ at $760{ }^{\circ} \mathrm{C}$ is more sensitive to strain variation than at $980{ }^{\circ} \mathrm{C}$. The contrary temperature dependence of $N_{\mathrm{f}}$ under various strain ranges can be attributed to the variation of crack initiation modes.

Under high strain range, the intense stress localization of DD10 alloy completes in a very short time due to the high $\Delta \varepsilon_{\mathrm{p}}$ and its poor plastic property at $760{ }^{\circ} \mathrm{C}$. However, at $980{ }^{\circ} \mathrm{C}$, only a high $\Delta \varepsilon_{\mathrm{p}}$ is not enough to lead to crack initiation, and an adequate time is needed for oxidation damage. Additionally, superior plasticity makes the local stress concentration much more difficult to happen. So, the fatigue life at $980{ }^{\circ} \mathrm{C}$ is longer, as shown in Fig. 6c and d, micro-crack is not visible at surface of DD10 alloy through 30 cycles at $980{ }^{\circ} \mathrm{C}$, whereas specimens at $760{ }^{\circ} \mathrm{C}$ have already failed.

Under low strain range, more severe oxidation damage occurs on DD10 alloy at $980{ }^{\circ} \mathrm{C}$, for the elongated exposure time induced by a decrease in $\Delta \varepsilon_{\text {total }}$. At the same time, the $\Delta \varepsilon_{\mathrm{p}}$ cannot be ignored at $980{ }^{\circ} \mathrm{C}$ (Table 2). However, the $\Delta \varepsilon_{\mathrm{p}}$ value is small at $760{ }^{\circ} \mathrm{C}$. According to the tensile test results in Table 2 , the alloy yields when the strain reaches about $0.83 \%$ at $760{ }^{\circ} \mathrm{C}$. Therefore, the crack 
initiation process experiences more cycles for the accumulation of local plastic deformation around defects. As shown in Fig. 6a and b, no micro-crack is visible around micro-pores at subsurface for DD10 specimens through 1,500 cycles at $760{ }^{\circ} \mathrm{C}$, but specimens in the same cycle condition at $980{ }^{\circ} \mathrm{C}$ have already failed.

\section{Conclusions}

Under low strain range, the fatigue life of DD10 at $760{ }^{\circ} \mathrm{C}$ is longer than that at $980^{\circ} \mathrm{C}$, but under high strain range, the contrary result is obtained. Different crack initiation mechanisms result in the reverse temperature dependence of the LCF life. At $760{ }^{\circ} \mathrm{C}$, plastic strain is the key factor of local stress concentration for limited slip systems, whereas both of plastic strain and oxidation damage play the dominant role together at $980{ }^{\circ} \mathrm{C}$.

Acknowledgments This work was financially supported by the National Basic Research Program of China (Nos. 2012AA03A511 and 2012AA03A513), and the National Natural Science Foundation of China (Nos. 51101160 and 51171193).

\section{References}

[1] N. Matan, D.C. Cox, P. Carter, M.A. Rist, C.M.F. Rae, R.C. Reed, Acta Mater. 47, 1549 (1999)

[2] J.S. Miao, T.M. Pollock, J.W. Jones, Acta Mater. 57, 5964 (2009)

[3] J.J. Moverare, S. Johansson, R.C. Reed, Acta Mater. 57, 2266 (2009)

[4] D.W. MacLachlan, D.M. Knowles, Metall. Mater. Trans. A 31, 1401 (2000)

[5] J. Zhang, J. Wang, H. Harada, Y. Koizumi, Acta Mater. 53, 4623 (2005)

[6] M. Valsan, D.H. Sastry, K.B.S. Rao, S.L. Mannan, Metall. Mater. Trans. A 25, 159 (1994)

[7] H.U. Hong, J.G. Kang, B.G. Choi, I.S. Kim, Y.S. Yoo, C.Y. Jo, Int. J. Fatigue 33, 1592 (2011)
[8] D.Q. Shi, J. Huang, X.G. Yang, H.C. Yu, Int. J. Fatigue 49, 31 (2013)

[9] T.P. Gabb, J. Gyda, Metall. Mater. Trans. A 17, 497 (1984)

[10] F. Jiao, D. Bettge, W. Osterle, J. Ziebs, Acta Mater. 44, 3933 (1996)

[11] X. Ma, H. Shi, J. Gu, Z. Wang, H. Harders, T. Malow, Acta Mech. Solida Sin. 21, 289 (2008)

[12] K. Prasad, R. Sarkar, P. Ghosal, V. Kumar, M. Sundararaman, Mater. Sci. Eng. A 568, 239 (2013)

[13] Y. Zhufeng, T. Xiande, Y. Zeyong, L. Haiyan, Appl. Math. Mech. 21, 415 (2000)

[14] L.Z. He, Q. Zheng, X.F. Sun, H.R. Guan, Z.Q. Hu, K. Tieu, C. Lu, H.T. Zhu, Mater. Trans. 47, 67 (2006)

[15] Z. Chu, Y. Jinjiang, S. Xiaofeng, G. Hengrong, H. Zhuangqi, Mater. Sci. Eng. A 488, 389 (2008)

[16] L.Z. He, Q. Zheng, X.F. Sun, H.R. Guan, Z.Q. Hu, A.K. Tieu, C. Lu, H.T. Zhu, Mater. Sci. Eng. A 402, 33 (2005)

[17] H.C. Yu, Y. Li, X.R. Wu, X.G. Yang, D.Q. Shi, Fracture Mech. Symp. 4, 57 (2006)

[18] K. Gopinath, A.K. Gogia, S.V. Kamat, R. Balamuralikrishnan, U. Ramamurty, Acta Mater. 57, 3450 (2009)

[19] E.R. Golubovskiy, I.L. Svetlov, N.V. Petrushin, S.A. Cherkasova, M.E. Volkov, Russ. Metall. (Met.) 2010, 941 (2011)

[20] E. Fleury, L. Remy, Mater. Sci. Eng. A 167, 23 (1993)

[21] K. Obrtlik, M. Petrenec, J. Man, J. Polak, K. Hrbacek, J. Mater. Sci. 44, 3305 (2009)

[22] M. Ott, H. Mughrabi, Mater. Sci. Eng. A 272, 24 (1999)

[23] J. Reuchet, L. Remy, Mater. Sci. Eng. 58, 19 (1983)

[24] J. Yao, J.T. Guo, C. Yuan, Z.J. Li, Acta Metall. Sin. 41, 357 (2005). (in Chinese)

[25] L.J. Chen, Z.G. Wang, G. Yao, J.F. Tian, Int. J. Fatigue 21, 791 (1999)

[26] D.C. Lord, L.F. Coffin, Metall. Trans. 4, 1647 (1973)

[27] R. Alain, P. Violan, J. Mendez, Mater. Sci. Eng. A 229, 87 (1997)

[28] Y.L. Lu, L.J. Chen, G.Y. Wang, M.L. Benson, P.K. Liaw, S.A. Thompson, J.W. Blust, P.F. Browning, A.K. Bhattacharya, J.M. Aurrecoechea, D.L. Klarstrom, Mater. Sci. Eng. A 409, 282 (2005)

[29] A. Defresne, L. Remy, Mater. Sci. Eng. A 129, 45 (1990)

[30] D. MacLachlan, D. Knowles, Fatigue Fract. Eng. M 24, 503 (2001)

[31] Y. Murakami, M. Endo, Int. J. Fatigue 16, 163 (1994)

[32] C.L. Brundidge, D. Vandrasek, B. Wang, T.M. Pollock, Metall. Mater. Trans. A 43, 965 (2012) 